\title{
Acute Accidental Formic Acid Poisoning: A Common Problem Reported in Rubber Plantations in Sullia
}

\author{
Sudhir M Naik, S Ravishankara, Mohan K Appaji, MK Goutham, Nonthombam Pinky Devi \\ Annapurna S Mushannavar, Sarika S Naik
}

\begin{abstract}
Background: Ingestion of formic acid, accidentally or with suicidal intention is a common problem among the workers in rubber plantations in Sullia. The diluted form of formic acid is used in coagulation of rubber latex. Sullia, a small town in South India, is well known for its rubber plantations. Easy accessibility to formic acid makes it susceptible to be used for committing suicide in this region. Also accidental ingestion are very common in these workers.
\end{abstract}

Aim: To study a case report of accidental formic acid poisoning and its management.

\begin{abstract}
Intervention: The patient was managed successfully by medical line of treatment. No gastric lavage or antidote was used in treatment and no vomiting induced. Nasogastric tube feeding was done and electrolyte imbalance was corrected.
\end{abstract}

Conclusion: Easy availability of formic acid should be curtailed by enforcing statutory limitations in its distribution and the complication of formic acid poisoning should be educated to these rubber workers. Patients with hematemesis or melena, after successful treatment, should be followed up with serial esophagogastroduodenoscopy for diagnosis and early treatment of strictures.

Keywords: Formic acid, Hematemesis, Esophagogastroduodenoscopy, Metabolic acidosis.

How to cite this article: Naik SM, Ravishankara S, Appaji MK, G outham MK, Devi NP, Mushannavar AS, Naik SS. Acute Accidental Formic Acid Poisoning: A Common Problem Reported in Rubber Plantations in Sullia. Int J Head Neck Surg 2012;3(2):101-105.

\section{Source of support: Nil}

Conflict of interest: None declared

\section{INTRODUCTION}

Sullia is a small town situated in the southern region of the Indian subcontinent and has a total population of nearly 1 lakh. The economy is predominantly agricultural. A recanut farming and growing rubber are the major agricultural produce. The labor is family-based and those engaged in rubber production collect the latex from the trees by tapping, harden it at once by admixture with formic acid and then bring it to the homestead for further processing prior to sale in sheet form.

The formic acid required for this purpose is readily available commercially, with the minimum of control of sale and supply. So, it is easily accessible to all members of those families working with rubber industry, as well as to their friends and neighbors. In this territory, the common methods of suicide are by hanging, drowning, ingestion of pesticides and different corrosives. A s formic acid is easily available to the rubber growing population suicidal ingestion and accidental ingestion is commonly seen in this region.

A part from its use in rubber industry as a latex coagulating agent, formic acid is al so used in electroplating, tanning and paper industries. It is also used in production of disinfectants and decalcifying agents. ${ }^{1}$ Formic acid is pungent and corrosive, so it is rarely swallowed accidentally. ${ }^{1}$ It is mixed with alcohol and consumed while committing suicide. ${ }^{1}$

Complications of ingestion of formic acid, the diluted form of which is used in coagulation of rubber latex, are common in this rubber growing belt. ${ }^{2}$ This is a case study of a patient who had accidental formic acid poisoning and was managed successfully in our KVG Medical College Hospital. This case study aims at studying the patterns of presentation and identifying the predictors of morbidity and mortality of acute formic acid poisoning and their successful management.

\section{CASE REPORT}

A 40-year-old patient presented to our ENT, H ead and N eck OPD with history of accidental consumption of formic acid. He complained of severe pain in the throat with absolute dysphagia. The patient had accidental consumption of nearly $20 \mathrm{ml}$ of concentrated formic acid which is used in preparing rubber latex. The patient immediately felt the mistake and spitted it out. Later, he induced vomiting to clear his throat. He cleansed the throat with water and tried to consume cold milk. He could not drink the cold milk because of dysphagia. He immediately came to a doctor where he was given first aid and referred to us. The patient was managed in accident and emergency casualty. The airway of the patient was maintained and saturation was well above $96 \%$.

Oral cavity examination showed intense corrosion of the tongue (Fig. 1) and the oral mucosa (Fig. 2). Indirect laryngoscopic examination was not possible. The serum electrolyte concentration levels were; serum sodium -143.0 meq/liter and serum potassium - 4.2 meq/liter. Blood reports showed $\mathrm{Hb} \%-13.0 \mathrm{gm} \%$, total RBC count 5.56 cell $\mathrm{s} / \mathrm{mm}^{3}$, total WBC count 18,600 cells $/ \mathrm{mm}^{3}$, platelet count -2.68 lakh cells $/ \mathrm{mm}^{3}$, polymorohs- $94 \%$, lymphocytes- $4 \%$, 


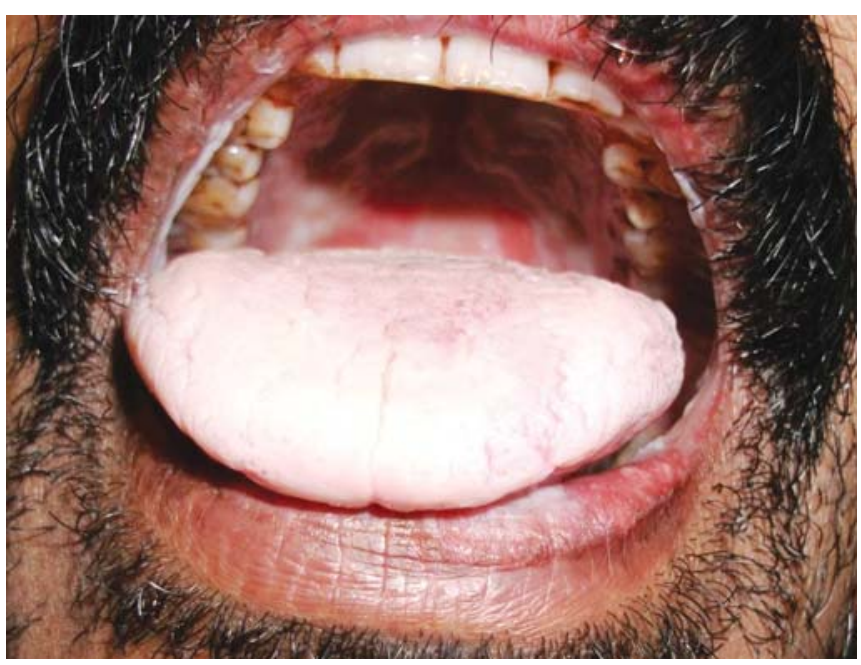

Fig. 1: Corrosion of the tongue due to accidental formic acid ingestion

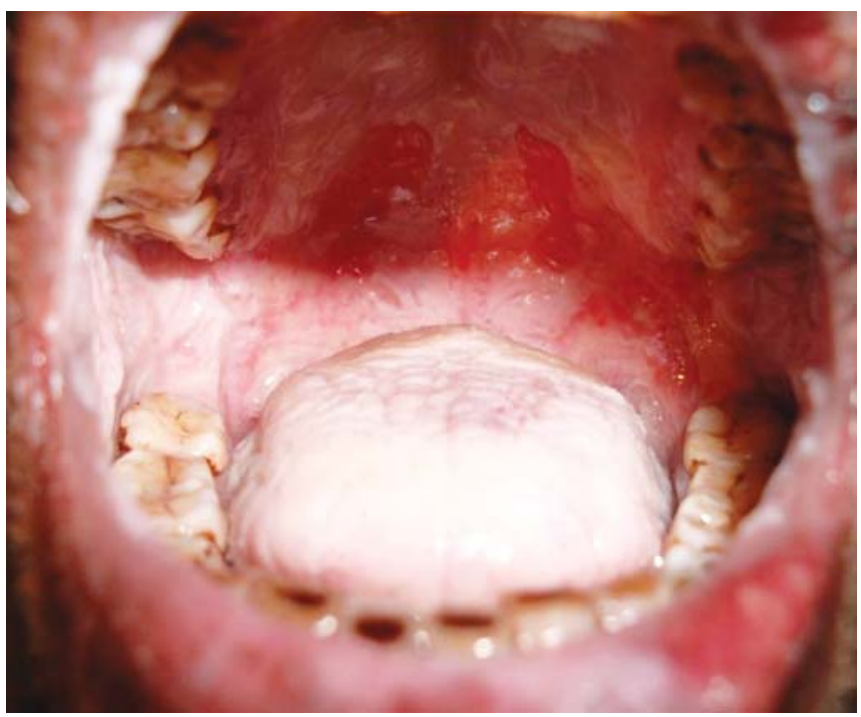

Fig. 2: Corrosion of the tongue and oral cavity due to accidental formic acid ingestion

eosinophils - 2\%. In the peripheral smear RBC's are normocytic normochromic in picture having a few macrocytic normochromic cells. Total count appears to be having mild leukocytosis.

Differential count shows severe neutrophilic leukocytosis and platelets were adequate in number and normal in size. Overall the peripheral smear was showing severe neutrophilia. X-ray lateral view of the neck showed swelling of the epiglottis with inflammatory edema of the posterior pharyngeal wall and laryngeal inlet structures (Fig. 3). Chest $X$-ray posterior-anterior view was clear with no signs of aspiration pneumonitis (Fig. 4).

The patient was put on high-dose of intravenous (IV) hydrocortisone $100 \mathrm{mg}$ twice daily for 3 days as the patient did not have severe GIT bleeding. Other treatment given were IV antibiotic ceftriaxone $1 \mathrm{~g}$ twice daily for a week,

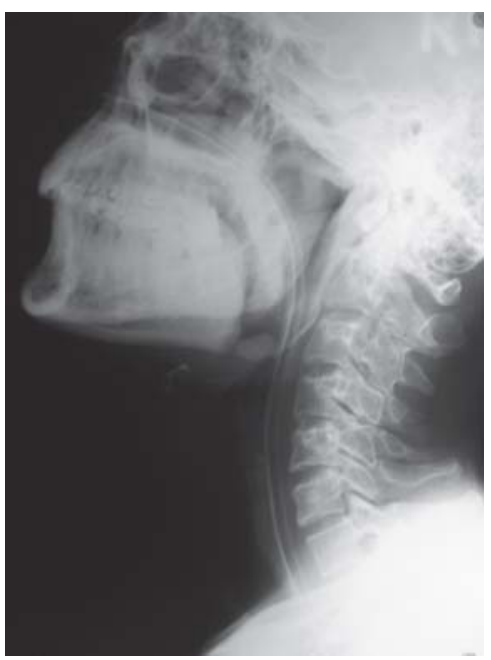

Fig. 3: Epiglottis and posterior pharyngeal wall swollen due to accidental formic acid ingestion

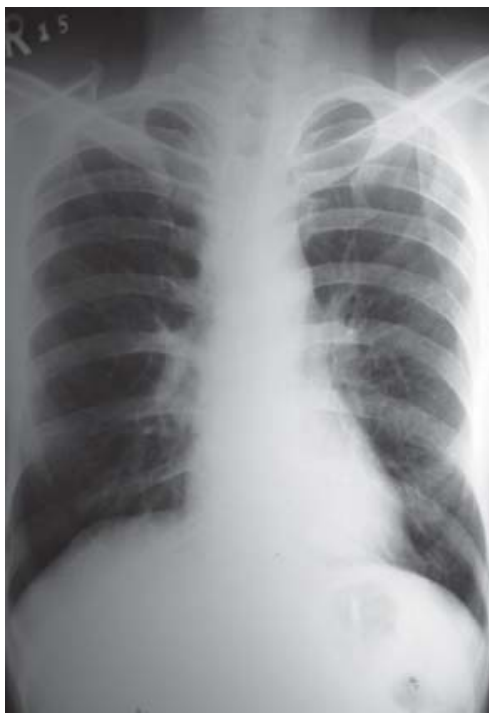

Fig. 4: Chest $X$-ray showing normal lung shadow

dexamethasone $8 \mathrm{mg}$ thrice daily for a week and IV pantoprazole $40 \mathrm{mg}$ twice daily for a week. The patient was maintained on parenteral IV fluids for 12 hours. A fter 24 hours when no severe damage to the GIT was suspected nasogastric tube was inserted and feeding was continued.

The patient was comfortable after 48 hours with no pain and tendency to frequently clear the throat had subsided. $N$ asogastric tube was (Fig. 5) removed after 5 days and oral cavity examined. A layer of oral mucosa came out after oral rinsing. $X$-ray of the lateral view of the neck was repeated, which showed reduction in swelling of the epiglottis (Fig. 6).

The barium swallow (Fig. 7) of the patient was done after removal of the nasogastric tube which showed normal contour of the esophagus. The pharyngeal lumen showed irregularity. The patient complained of mild dysphagia at 


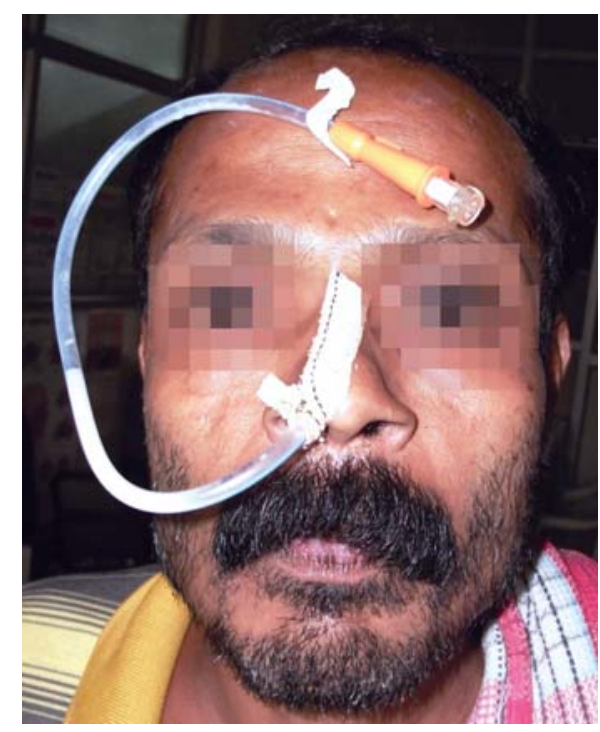

Fig. 5: Nasogastric tube inserted

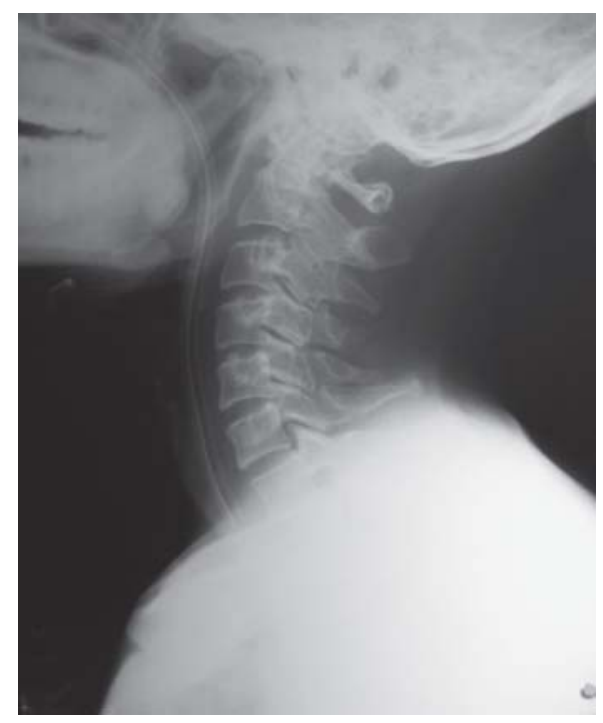

Fig. 6: Swelling of the epiglottis and posterior pharyngeal wall reduced after 5 days of treatment

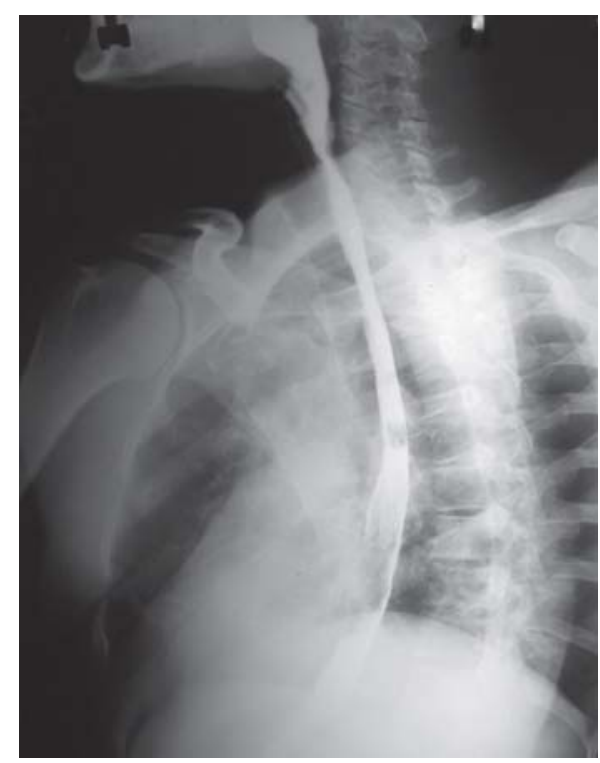

Fig. 7: Normal barium swallow on 7th day

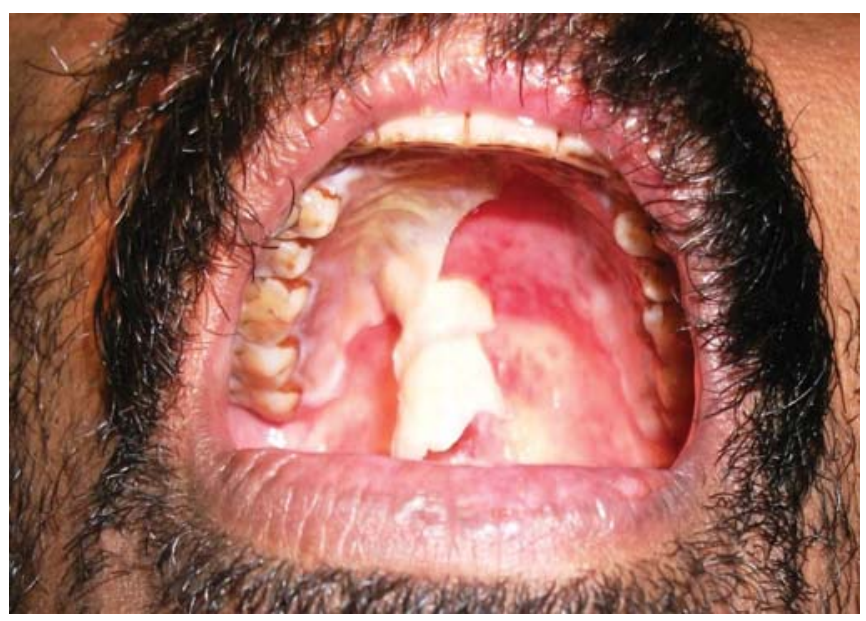

Fig. 8: Corroded oral mucosa peeled out

the time of discharge. Oral cavity examination showed a red congested mucosa (Fig. 8). Esophagogastroduodenoscopy was done on the 7th day after accidental ingestion, the mucosal pattern showed erythema of the upper one-third esophagus and no hemorrhagic areas seen. The patient was discharged after 7 days with minimal dysphagia. The patient was followed up for 4 months with serial esophago-gastroduodenoscopy and no complications were observed. The patient did not complain of dysphagia and was symptom free after 4 months.

\section{DISCUSSION}

Formic acid is a colorless liquid with pungent penetrating odor. ${ }^{2}$ The fatal dose is 50 to $200 \mathrm{ml}^{2}{ }^{2}$ U sually, the victims are males in the middle age group. ${ }^{2} \mathrm{~N}$ early $90 \%$ of cases of formic acid poisoning are with intention of suicide and only $10 \%$ are accidental consumption. ${ }^{2}$ It is observed that most of the victims mix formic acid with alcohol while swallowing it for suicidal purpose. ${ }^{2}$

Most common clinical features at the time of presentation are vomiting, respiratory distress, hematemesis and hematuria. ${ }^{3} \mathrm{~F}$ resh blood vomitus and frank fresh blood per rectum may start early with 30 to $40 \mathrm{ml}$ of ingestion of formic acid. ${ }^{3,4}$ Patient will complain of acute abdominal pain and pass dark red urine. ${ }^{3,4} \mathrm{M}$ ost common complications of the poisoning observed were oral cavity burns, metabolic acidosis, septicemia, dysphagia, esophageal stricture, gastrointestinal perforation, aspiration pneumonia, acute respiratory distress syndrome (ARDS), acute renal failure, chemical pneumonitis and shock. ${ }^{3,4}$ Erythema and blisters are common, if the formic acid is accidentally splashed on to the face or the skin at the time of the suicidal attempt. ${ }^{3,4}$ Rare complications were tracheoesophageal fistula, pneumomediastinum and chemical injury to the cornea. ${ }^{3,4}$

The corrosive effect of the formic acid on the oral mucosa is manifested as burning pain, excessive salivation, 
intense vomiting, mucosal corrosion and ulceration, hematemesis and also as gastric ulcerations. ${ }^{3,4}$ It is readily absorbed from the gastrointestinal tract. ${ }^{3,4}$ Coagulative necrosis of the gastrointestinal mucosa occurs as a result of its corrosive action. ${ }^{3,4}$ It also damages the clotting factors and causes hemolysis leading to acute renal failure. ${ }^{3,4} \mathrm{At}$ the cellular level, it has inhibitory action on aerobic glycolysis with consequent dimunition of A TP synthesis. ${ }^{3,4}$ Blood examination may show varying degree hemolysis and disseminated intravascular coagulation. Severe clotting factors defect may be seen and should be monitored by bleeding time and clotting time. ${ }^{3,4}$ They are confirmed by prothrombin time, thrombin time, serum fibrinogen and serum fibrinogen degradation products. Serial platelet counts are monitored. ${ }^{3,4}$

Patient may present with drowsiness, weakness all over the body, with pupils completely dilated. ${ }^{3,4}$ The patient may present with tachycardia or bradycardia, hypertension or hypotension. ${ }^{3,4}$ The changes in the cardiovascular system are nonspecific, both brady- and tachyarrhythmias being observed, frequently accompanied by profound vascular hypotension. ${ }^{1,3,4}$

A cute respiratory distress syndrome, aspiration pneumonitis and shock lung are the fatal respiratory complications manifested in severe poisoning. ${ }^{5}$ Inhalation pneumonitis which manifests as cough, dyspnea and cyanosis, can complicate as chemical pneumonitis and respiratory failure..$^{5}$ They usually present on the 3rd to 4 th days later and may need ventilatory support. ${ }^{5}$

Metabolic acidosis may be profound with $\mathrm{pH}$ nearing 7, this should be treated intensively with IV sodium bicarbonate. ${ }^{5} \mathrm{Nill}$ per orally should be maintained and total parenteral nutrition advised. ${ }^{6}$ If severe gastrointestinal hemorrhage is seen, no steroids should be given as it may precipitate impending perforation of the gut wall. ${ }^{6}$ OGD should not be done. ${ }^{6}$

The patient should be immediately admitted. ${ }^{6} \mathrm{~V}$ omiting should not be induced and gastric lavage should not be attempted. ${ }^{6} \mathrm{No}$ role of activated charcoal exists in formic acid poisoning management. ${ }^{6} \mathrm{High}$ doses of folinic acid ( $1 \mathrm{mg} / \mathrm{kg}$ IV bolus followed by 6 doses of $1 \mathrm{mg} / \mathrm{kg}$ IV doses at 4th hourly intervals) should be given in severe poisoning. Folinic acid acts by enhancing formate degradation in the liver. ${ }^{7}$ If electrolyte imbalance is uncorrectable by intravenous supplementation hemodialysis should be considered. ${ }^{7}$ Exchange transfusion should be considered in conditions of severe intravascular hemolysis. ${ }^{1}$ Devastating changes may be seen in the renal system, with hematuria usually appearing within a few hours of ingestion of the acid. ${ }^{8} \mathrm{~A} n$ intense watch should be kept on serem creatinine levels, urine output and serum potassium levels to detect early onset of acute renal failure. ${ }^{8}$ E arlier acute renal failure were corrected by peritoneal dialysis ${ }^{8}$ nowadays hemodialysis is preferred. ${ }^{9}$ Hypovolemia due to blood loss was corrected by whole blood transfusions. ${ }^{9}$

In cases of shock intubation and ventilatory support are essential to maintain oxygen saturation. ${ }^{9}$ Correction of metabolic acidosis and renal failure, if it sets in should be done. ${ }^{9}$ Fatal intoxication after oral ingestion of high doses of formic acid are frequently due to acid induced severe damage to the gastric wall with perforation. ${ }^{9}$ In cases without severe local lesions, death is caused by massive acidosis, excessive hemolysis and bleeding. ${ }^{9}$ The majority of the lesions were evident in the gastrointestinal tract, with facial (typically circumoral) burns and ulceration of the oral and pharyngeal mucosa. ${ }^{9} \mathrm{~A}$ bdominal pain was accompanied by hematemesis and dysphagia. ${ }^{9}$

Later complications included contractures and keloid formation on the affected area of the skin and notably, esophageal stricture, for which reparative surgery should be done. ${ }^{10}$ Progress should be monitored by the usual biochemical and hematological investigations, including bleeding and clotting times. ${ }^{10}$ In cases where severe gastrointestinal hemorrhage was seen, barium swallow and serial OGD were performed during follow-up. ${ }^{10}$ OGD sometimes reveals florid hemorrhagic esophagitis. ${ }^{10}$

In a study where a retrospective analysis of 15 deaths due to formic acid poisoning were done, ${ }^{6}$ had succumbed to severe vascular hypotension and respiratory arrest, four died of acute renal failure and five failed to recover from gastrointestinal hemorrhage. Ten milliliters by mouth could prove lethal, death then taking place within hours, regardless of treatment. Those believed to have taken $15 \mathrm{ml}$ to a mouthful were likely to be found dead.

No specific antidote is available and so treatment is essentially supportive. ${ }^{10}$ A ntacids, milk and egg- white were cautiously administered orally, if no gastrointestinal hemorrhage is suspected. If GIT hemorrhage is suspected, patients should be maintained nil orally. Intravenous fluids and electrolytes were infused to counter 'shock' and antibiotics ${ }^{10}$ were indicated prophylactically to prevent infection. ${ }^{10}$ Diuretics promote renal function in acute renal failure. ${ }^{10} \mathrm{Hydrocortisone}$ counters stress and inflammation but should be only be given in case where no GIT hemorrhage is seen otherwise perforation results. ${ }^{10}$

When the acute emergency of gastrointestinal hemorrhage, metabolic acidosis, renal failure are all settled, pain relief should be given to the patient preferably with diamorphine. ${ }^{11}$ If the patient is anxious and irritable sedation can be given in low doses of diazepam. ${ }^{11} \mathrm{~L}$ ocal pain relief 
Acute Accidental Formic Acid Poisoning: A Common Problem Reported in Rubber Plantations in Sullia

can be given by local irrigations of $5 \%$ lignocaine viscous or $15 \%$ lignocaine spray. ${ }^{11}$

In Sullia town, accidental poisoning, suicide and attempted suicide with formic acid are all treated as medicolegal cases and suicide and attempted suicide as crimes. A II the patients are reported to the police authorities except accidental cases.

\section{CONCLUSION}

Hematemesis and melena had significant association with esophageal stricture. Hematuria, respiratory distress, hematemesis and gastrointestinal perforation at presentation were significantly associated with mortality. M etabolic acidosis with $\mathrm{pH}<7.3$, hematemesis and age more than 40 are independent predictors of morbidity. Even if the patients survives the patient may have long standing problems of esophageal stricture which may need serial dilatations later. Skin scarring and disfigurement should be corrected by cosmetic surgery.

Education about safe handling of the formic acid and dangers of consumption should be educated to the rubber growing population of Sullia.

\section{SUMMARY}

Since, formic acid is so readily accessible to the laborers of the rubber cultivating community in Sullia, it is the easiest means of corrosive poisoning in this region. Easy availability of formic acid should be curtailed by enforcing statutory limitations in its distribution and spreading the knowledge of its side-effects.

M etabolic acidosis, if taken care of by administration of sodium bicarbonate intravenously at the local medical centers, before referring the patient to a tertiary setup, may reduce mortality and morbidity in acute formic acid poisoning. Patients with hematemesis or melena, if they survive, should be followed up with serial OGD for diagnosis and early treatment of strictures.

\section{REFERENCES}

1. Malizia E, Reale C, Pietropaoli P, De Ritris GC. Formic acid intoxications. Acta Pharmacologica et Toxicologica (Suppl.) 1977; 41:342.

2. Rajan N, Rahim R, Krishna S Kumar. Formic acid poisoning with suicidal intent: A report of 53 cases. Postgrad Med J 1985;61:35-36.

3. Naik RB, Stephens WP, Wilson DJ, Walker A, Lee HA. Ingestion of formic acid-containing agents: R eport of three fatal cases. Postgrad M ed J 1980;56:451.

4. Sujathan $G$, J ayapalan VK. Formic acid poisoning. J Ind A cad Forensic M ed 1991;13:29-31.
5. W iernickowski A, Guzik E. Ostre zatrucie kwasem mr6wkowym [A cute poisoning with formic acid.] Przeglad Lekarski 1973;30:395.

6. Estresa A, Taylor W, M iller LJ, et al. Corrosive burns of the esophagus and stomach: A remainder for aggressive surgical approach. A nn Thoracic Surg 1986;41:276-83.

7. M oore DF, B entley AM, Dawling S, Hoase AM, Henry JA. Formic acid and enhanced renal elimination in formic acid intoxication. Clinical Toxicol 1994;32:199-204.

8. K rishna K umar S, Rajan N, M athew Roy, V C. Peritoneal dialysis in acute renal failure following viper bite. Kerala M ed J 1975;15:1975.

9. W estphal F, Rochholz G, Ritz-Timme S, B ilzer N, Schütz HW, $\mathrm{K}$ aatsch $\mathrm{HJ}$. Fatal intoxication with a decalcifying agent containing formic acid. Int J Leg Med 2001 Feb;114(3): 181-85.

10. W ebb WR, K outran P, Ecker RR, et al. A n evaluation of steroids and antibiotics in corrosive burns of esophagus. Ann Thoracic Surg 1970;9:95-102.

11. Berlyne G M , Henry J ones J, H ewitt V , N ilwarangkur S. Protein loss in peritoneal dialysis. L ancet 1964;1:738.

\section{ABOUT THE AUTHORS}

\section{Sudhir M Naik (Corresponding Author)}

A ssociate Professor, D epartment of ENT and Head and N eck Surgery KV G M edical College and H ospital, Kurunjibag, Sullia, K arnataka India, Phone: 919916807109, e-mail: sud223@gmail.com

\section{S Ravishankara}

A ssociate Professor, D epartment of ENT and H ead and N eck Surgery K V G M edical Collegeand Hospital, K urunjibag, Sullia, K arnataka, India

\section{Mohan K Appaji}

Professor and $\mathrm{H}$ ead, Department of ENT and H ead and Neck Surgery KV G M edical College, Hospital, Kurunjibag, Sullia, K arnataka, India

\section{MK Goutham}

Senior R esident, D epartment of ENT and Head and Neck Surgery, KV G M edical College and Hospital, K urunjibag, Sullia, Karnataka, India

\section{Nonthombam Pinky Devi}

Senior R esident, Department of ENT and Head and N eck Surgery, K V G M edical College and H ospital, K urunjibag, Sullia, Karnataka, India

\section{Annapurna S Mushannavar}

Senior R esident. Department of ENT and Head and Neck Surgery, KV G M edical College and Hospital, K urunjibag, Sullia, K arnataka, India

\section{Sarika S Naik}

Senior Resident, Department of A nesthesia and Critical Care Narayana Hrudayalaya, B engaluru, K arnataka, India 